DOI: http://dx.doi.org/10.11606/issn.1984-4867.v26i4p859-879

\title{
Competitividade de Destinos Turísticos na Visão da Demanda: introdução de um novo método de avaliação
}

\section{Competitiveness of Tourist Destinations According to the Customers'View: introduction of a new method of assessment}

\section{Competitividad de los Destinos Turísticos de Acuerdo a la Opinión de los Clientes: introducción de un nuevo método de evaluación}

Edar da Silva Añaña ${ }^{1}$

Melise de Lima Pereira ${ }^{2}$

Francisco Antônio dos Anjos ${ }^{3}$

\section{Resumo}

O presente artigo avalia a competitividade de uma cidade interiorana enquanto destino turístico, em relação aos principais destinos concorrentes. O trabalho introduz uma metodologia inovadora para medir a competitividade de destinos turísticos segundo a visão da demanda, baseada no mapeamento perceptual dos respondentes, que permite avaliar as principais forças e fraquezas percebidas no destino, e compará-las as dos principais concorrentes. Além da avaliação subjetiva, feita pelo mapeamento perceptual, o método proposto também utiliza a Análise Fatorial Exploratória para avaliar objetivamente as medidas de performance do destino, e compara-las aos destinos concorrentes. O trabalho inova em relação aos seus antecedentes, na medida em que o método proposto permite ao mesmo tempo identificar os principais concorrentes do destino e avaliar o seu desempenho, tanto em relação às expectativas dos clientes, quanto em relação aos principais concorrentes. Embora encorajadores, os resultados devem ser tomados com cuidado, tendo em vista que a amostra tem grande parcela de estudantes e que foi colhida por conveniência, através da internet, o que não permite maior controle sobre os respondentes.

Palavras-chave: Turismo; Competitividade; Destino.

\begin{abstract}
This article assesses the competitiveness of an inland city as a tourist destination, in relation to its key competitors. The work introduces a new method to measure the competitiveness of

1 Professor de Marketing da Universidade Federal de Pelotas - UFPEL. Doutor em Administração pela Universidade Federal do Rio Grande do Sul. Pelotas-RS, Brasil. E-mail: edaranana@gmail.com.

2 Professora nos cursos de Bacharelado em Turismo Binacional, Bacharelado em Hotelaria e Tecnologia em Eventos da Universidade Federal do Rio Grande - FURG. Instituto de Ciências Humanas e Informação. Doutoranda em Turismo e Hotelaria pela Universidade do Vale do Itajaí - UNIVALI. Santa Vitória do PalmarRS, Brasil. E-mail: melisedelimapereira@gmail.com.

3 Professor do Mestrado e Doutorado em Turismo e Hotelaria da Universidade do Vale do Itajaí - UNIVALI. Doutor em Engenharia de Produção e Gestão Ambiental pela Universidade Federal de Santa Catarina. Balneário Camboriú-SC, Brasil. E-mail: anjos@univali.br.
\end{abstract}


tourist destinations through the eyes of the customers, based on perceptual mapping of respondents, which allows evaluation of the main strengths and weaknesses perceived by the audience, and compare them with competitors' competiveness. In addition to the subjective evaluation through perceptual mapping, the proposed method also uses Exploratory Factor Analysis to evaluate the destination's performance objectively, and to compare them with the main competitors. The work is innovative in relation to the precedents, once the proposed method allows simultaneously identify the main competitors for a tourist destination and evaluate their performance both in relation to the customers' expectations, and in comparison to the key competitors. Although encouraging, results shall be taken with care, given that the sample have a large portion of students and that it was gathered by convenience over the internet, a method that does not allow much control over respondents' behaviour.

Keywords: Tourism; Competitiveness; Destination.

\section{Resumen}

En este artículo se evalúa la competitividad de una ciudad del interior como destino turístico, en relación con sus principales competidores. El trabajo presenta un nuevo método para medir la competitividad de los destinos turísticos a través de los ojos de los clientes, en base a la cartografía de percepción de los encuestados, que permite la evaluación de las principales fortalezas y debilidades percibidas por el público, y compararlos con la competitividad de los competidores. Además de la evaluación subjetiva a través del mapeo perceptual, el método propuesto también utiliza análisis factorial exploratorio para evaluar el desempeño del destino de manera objetiva, y compararlos con los principales competidores. El trabajo es innovador en relación a los precedentes, una vez que el método propuesto permite identificar simultáneamente los principales competidores para un destino turístico y evaluar su desempeño tanto en relación con las expectativas de los clientes, y en comparación con los principales competidores. Aunque alentadoras, los resultados deben ser tomados con cuidado, teniendo en cuenta que la muestra tiene una gran parte de los estudiantes y que se reunieron por conveniencia en internet, un método que no permite mucho control sobre la conducta de los encuestados.

Palabras-clave: Turismo; Competitividad; Destino.

\section{Introdução}

Os estudos da competitividade do destino são relativamente recentes, e raros ainda são os trabalhos empíricos (ENRIGHT; NEWTON, 2004). A medição da competitividade através de indicadores ou construção de modelos também é escassa nos estudos nacionais, bem como nos internacionais (MIKI, GÂNDARA; MUÑOZ, 2012). Conforme Crouch (2007), o interesse por compreender e mensurar a competitividade dos destinos emergiu nos anos 90 e cresceu na última década, quando trabalhos empíricos passaram a identificar outros fatores de competitividade além do preço. Boa parte dos modelos recentes (BUHALIS, 2000; RITCHIE; 
CROUCH, 1999，2000，2003; GOOROOCHURN; SUGIARTO, 2005; MAZANEC, WOBER; ZINS, 2007) tratam a competitividade de forma integrada, como um conjunto de facilidades capaz de tornar mais ou menos competitivo um destino específico, especialmente países, ignorando, contudo, a valoração que os indivíduos (ou grupos) atribuem aos produtos turísticos.

Dwyer e Kim (2003) sugeriram um modelo integrativo com 150 indicadores de competitividade, organizados em quatro dimensões (recursos turísticos, gestão do destino, condições situacionais e condições da demanda) o qual não chegou a ser testado empiricamente. Enright e Newton (2004, 2005) identificaram um conjunto de 52 indicadores (15 atrações turísticas e 37 variáveis ligadas ao ambiente de negócios), que foram inseridos numa Matriz de Importância e Desempenho (IPA Grid) para avaliar a competitividade de Hong Kong (2004), e de Hong Kong, Singapura e Bangcoc (2005) como destinos turísticos. E Mazanec, Wober e Zins (2007) testaram um modelo estrutural com 27 indicadores, colhidos das contas nacionais de 169 países membros do Conselho Mundial de Viagens e Turismo (WTTC).

O presente estudo segue a mesma lógica de Enright e Newton $(2004,2005)$, na medida em que avalia a competitividade do destino a partir da posição relativa das variáveis numa Matriz de Importância e Desempenho, mas difere daqueles em foco e em profundidade analítica. Ao focar-se num destino interiorano (uma cidade), que tem no turismo nacional a sua principal fonte de entrada, o presente trabalho inova sobre os anteriores, que buscavam avaliar a competitividade de países inteiros; e em relação à profundidade analítica, este estudo é mais ambicioso que os anteriores, pois além do mapeamento das forças e fraquezas relativas, também identifica uma escala de medida que permite comparar a atratividade do destino com destinos concorrentes e acompanhar a sua performance ao longo do tempo.

O objetivo geral da pesquisa é avaliar a competitividade de uma cidade interiorana enquanto destino turístico, em relação aos destinos concorrentes. Dentre os objetivos específicos, destacam-se: identificar os fatores de competitividade do destino interiorano; Analisar a importância relativa dos atributos diretamente ligados ao turismo e dos atributos facilitadores do turismo; Identificar os principais destinos turísticos concorrentes; Analisar a performance competitiva do destino observando as forças e fraquezas, para gerar informações que permitam amparar o planejamento da atividade turística. A pesquisa caracteriza-se como exploratório-descritiva, com abordagem predominantemente quantitativa. 


\section{A Competitividade dos Destinos Turísticos}

Um destino se constitui numa amálgama de produtos turísticos, que são oferecidos e consumidos sob uma marca, a marca do destino. Leiper (1995), citado por Buhalis (2000), define destinos como lugares que as pessoas escolhem para permanecer durante um período de tempo, para usufruir de certas facilidades ou características percebidas como atrações. Para Cooper, Fletcher, Gilbert, Shepherd e Wanhill (1998), o destino é o foco das facilidades e serviços concebidos para satisfazer às necessidades dos turistas. E por se tratar de um composto de produtos e serviços, a competitividade do destino depende tanto das atrações turísticas propriamente ditas, quanto da receptividade da população, quanto da capacidade das empresas, do poder público e das organizações em geral, de prover uma estrutura de suporte que permita uma adequada prestação de serviços aos turistas.

Conforme Buhalis (2000), a maior parte dos destinos inclui um conjunto de componentes caracterizados como os seis 'A's: [A]trações, [A]cessibilidade, [A]menidades, Disponibilidade de p[A]cotes, [A]tividades e Serviços [A]uxiliares. Em consequência, o destino pode ser referido como uma combinação (ou mesmo uma marca) de produtos, serviços e experiências produzidos e consumidos localmente. Assim, independente da posse dos componentes, estes dificilmente são vinculados a um ou a outro fornecedor, já que representam uma coleção de interesses pessoais e profissionais de todas as pessoas que vivem na área do destino.

Ainda que a maior parte dos estudos referentes à competitividade se refira a destinos do tipo país (e não a localidades), todos eles reconhecem que para ser bem sucedido um destino precisa ter atratividade superior e entregar aos visitantes experiências mais prazerosas que os destinos concorrentes. E ao mesmo tempo algumas mudanças de postura sugerem a necessidade crescente de cooperação e colaboração em níveis local e regional para que os produtos turísticos possam concorrer em escala global (CROUCH; RITCHIE, 1999).

O conceito de competitividade é fortemente baseado na indústria de bens, ainda que o setor de serviços seja dominante nas economias desenvolvidas. Ainda que a economia de serviços seja fortemente dependente da demanda doméstica, o volume negociado internacionalmente vem crescendo rapidamente. E poucos pesquisadores examinaram a aplicabilidade da teoria das trocas internacionais ao comércio de serviços, mas "nada indica que estas sejam menos aplicáveis aos serviços" (CROUCH; RITCHIE, 1999, P. 142). 
Conforme Crouch (2007), a gestão da competitividade de um destino é um tema bastante complexo, tendo em vista estar sujeita a um grande número de forças, influências e eventos; que alguns atributos da competitividade são de difícil controle, por pertencerem a diferentes atores; e que o desenvolvimento turístico produz benefícios e custos (econômicos, sociais e ambientais) ao mesmo tempo. Mas apesar da complexidade que envolve o tema, a competição é um imperativo dos tempos atuais, "já que o aumento da mobilidade dos turistas permite que competidores em nível global, concorram com os destinos locais" (p. 24).

Para Mazanec, Wöber e Zins (2007), a melhor abordagem para a competitividade de destinos foi aquela sugerida por Ritchie e Crouch (2000), que ao longo de uma década de trabalho delimitaram a competitividade dos destinos a partir da dotação e do desenvolvimento dos recursos. A dotação de recursos humanos, físicos, de conhecimento, de capital, de infra e de superestrutura, a história e os recursos culturais criam as chamadas vantagens comparativas, e os recursos desenvolvidos (auditoria e inventário, manutenção, crescimento e desenvolvimento, eficiência e eficácia) criam as vantagens competitivas.

Embora se apresente como um conceito relativamente simples, a competitividade é um construto de difícil mensuração. Em sentido amplo, competitividade nada mais é senão a busca da superioridade em matéria de qualidade, entretanto, quando se tenta medir a competitividade de um destino (ou de outro negócio qualquer), percebe-se que se trata de um conceito relativo (superior em relação a o quê?) e multidimensional (quais são as qualidades importantes?) (CROUCH; RITCHIE, 1999).

Assim, para ser competitivo é preciso que o destino desenvolva e comunique os atrativos de interesse turístico (naturais ou criados), e organize as facilidades político-administrativoorganizacionais necessárias ao suporte da atividade. Conforme Crouch (2007), algumas fragilidades determinadas pela geografia física e pelo clima, são difíceis de serem compensadas por outros atributos de atração; mesmo assim um destino pode ser competitivo se souber explorar corretamente a cultura e a história, se criar uma superestrutura turística adequada à atração de eventos especiais, desenvolver um conjunto interessante de atividades de recreação e desenvolver uma imagem e uma reputação favoráveis. 


\section{Avaliação e Mensuração da Competitividade}

A mensuração de construtos teóricos é um desafio para praticamente todos os trabalhos desta natureza. Conforme o contexto e os objetivos da pesquisa, diversas estratégias podem ser empregadas para desenvolver e refinar os instrumentos de medida (BEARDEN, NETEMEYER; HAWS, 2011). No caso da competitividade dos destinos, como o construto é relativamente recente, poucos ainda são os trabalhos empíricos que discutem formas de avaliação. Entretanto, como se trata de um conceito relativo, é importante identificar e validar medidas objetivas que permitam comparar a força de atração de um destino com os destinos concorrentes, e/ou acompanhar a sua evolução ao longo do tempo.

Por se tratar de um construto multifacetado, uma forma de avaliar a competitividade de um destino turístico é fazê-lo através de indicadores ou de grupos de indicadores (escalas). Conforme Churchill Jr. (1979), a mensuração de construtos envolve a atribuição de números destinados a representar os atributos teoricamente relacionados ao conceito. $\mathrm{O}$ procedimento recomendado por aquele autor se desenvolve em quatro fases: (a) delimitação "do que está" e "do que não está" relacionado ao conceito, (b) identificação de um rol de atributos possivelmente representativos, (c) purificação da escala, através de Análise Fatorial, para eliminação de atributos desnecessários, e (d) avaliação da consistência interna.

Alguns autores têm sugerido possíveis vetores de competitividade, e até mesmo elencado listas de atributos, mas nenhum dos trabalhos revisados ousou purificar e validar uma escala de medida. Conforme Dwyer e Kim (2003), não existem [ainda] um conjunto único de indicadores que possa ser aplicado indiscriminadamente a todos os destinos e em todas as circunstâncias, o que reforça a necessidade de purificar uma escala a partir dos indicadores sugeridos pela literatura. Entre os trabalhos que identificam possíveis vetores de competitividade, destacam-se o de Enright, Scott e Dodwell (1997), citado por Enright e Newton (2004), que propõe um modelo baseado em seis forças: (a) as entradas; (b) a demanda industrial e de consumo; (c) a competição e a cooperação interfirmas; (d) os clusters industriais e regionais; (e) a organização e a estratégia das empresas; e (f) as instituições, as estruturas sociais e as agendas.

Crouch e Ritchie (1999) sugerem que a competitividade do destino turístico é determinada pela combinação de quatro grandes componentes: (a) os atrativos centrais; (b) os fatores e recursos de suporte; (c) a gestão do destino; e (d) os atributos qualificadores. Os atrativos 
centrais envolvem aspectos da geografia física (clima e paisagem), a história e a cultura, os mercados, as atividades, os eventos especiais e a superestrutura turística. Os fatores de suporte, como a infraestrutura em geral e a rede de educação e treinamento, constituem a base de apoio sobre a qual se assenta a competitividade da indústria turística. A gestão do destino favorece os outros componentes, na medida em que faz aflorar o apelo mercadológico dos atrativos centrais, e fortalece a qualidade e a efetividade dos fatores de suporte, adaptando o destino às restrições impostas pela natureza ou pelas circunstâncias. E os chamados atributos qualificadores reúnem algumas variáveis críticas, como a localização, os custos de produção e a segurança pública, variáveis sobre as quais os gestores turísticos têm pouca ou nenhuma influência, e que muitas vezes reduzem a competitividade do destino.

O trabalho de Enright e Newton (2004) propõe um modelo baseado numa Matriz de Importância e Desempenho, aqui tratado como MID (IPA Grid), que permite avaliar a competitividade de um destino a partir da distribuição das médias das variáveis num gráfico de duas dimensões, modelo que também foi aplicado por Taberner (2007). Através daquele método é possível identificar as variáveis mais e menos importantes para a competitividade do destino, assim como a força relativa de cada uma delas, na visão dos consumidores.

\section{Método}

O presente trabalho utiliza uma Matriz de Importância e Desempenho para mapear a posição relativa dos atributos, e avança no refinamento de uma escala de mensuração com base na técnica proposta por Churchill Jr. (1979), através da qual é possível comparar diversos destinos entre si e ao longo do tempo. A identificação de uma escala que permita medir os diferentes vetores de competitividade do destino estudado se justifica por tratar-se de um conceito relativo, uma medida de performance a ser comparada com os destinos concorrentes, o que não é possível com a simples aplicação do método empregado por Enright e Newton (2004) e por Taberner (2007).

A Análise de Importância e Desempenho (AID) é uma técnica gráfica, de precisão relativa, uma vez que a sua efetividade depende da correta distribuição dos atributos nos eixos e da interpretação visual do leitor. É uma técnica relativamente simples e de fácil interpretação, mesmo por pessoas sem maiores habilidades estatísticas (CROMPTON; DURAY, 1985). Consiste basicamente na construção de uma matriz de dupla entrada, cujos valores são 
plotados em um gráfico de duas dimensões, cujo eixo vertical expressa a importância de cada atributo para a formação da competitividade do destino, e o eixo horizontal a performance do destino avaliado em relação ao(s) destino(s) concorrente(s) (TABERNER, 2007).

Conforme a distribuição das variáveis nos quadrantes da figura é possível avaliar as forças e fraquezas do destino. Os atributos colocados no quadrante superior direito (alta importância e alta performance) são aqueles nos quais o destino se destaca: são itens importantes para a formação da competitividade, nos quais o destino supera aos concorrentes. O quadrante superior esquerdo reúne os itens problemáticos, atributos que são importantes para a formação da competitividade, mas que o destino é pouco competitivo. No quadrante inferior direito aparecem itens nos quais o destino se destaca, mas que possuem pouca importância relativa. $\mathrm{E}$ finalmente, no quadrante inferior esquerdo aparecem os atributos nos quais o destino tem pouca força, mas que, devido à baixa importância que os clientes atribuem aos mesmos para a formação da competitividade do destino, não requerem maior atenção.

A amostra utilizada foi colhida através de formulário eletrônico hospedado no endereço institucional de uma determinada Universidade, através do qual foram coletadas 140 respostas (109 válidas), entre os dias 06 e 19 de julho de 2014. Na página de abertura, o formulário esclarecia o objetivo da pesquisa e solicitava aos respondentes: (1) a informar os três destinos considerados como os mais fortes concorrentes do destino avaliado, (2) a classificar por ordem de importância dois conjuntos de atributos (atrativos turísticos e atributos facilitadores) e, finalmente (3) a avaliar a performance da cidade em relação ao principal concorrente, através dos 36 atributos, numa escala de cinco pontos que ia de "muito pior" a "muito melhor".

O rol de variáveis incluídas no instrumento (Tabela 1) foi adaptado de Enright e Newton (2004), com o apoio de dois pesquisadores em turismo fluentes no idioma inglês, que fizeram o papel de juízes. Os quinze atributos diretamente relacionados ao turismo foram vertidos para português e acrescidos da "hospitalidade da população local", considerada imprescindível ao caso estudado. Dezessete dos 37 atributos facilitadores do turismo foram considerados dispensáveis por se referirem diretamente ao mercado asiático ou a destinos do tipo país, e por isso eliminados.

Na próxima seção são descritos os principais achados do estudo. Inicialmente é relatado o resultado baseado na AID dos atributos, à luz dos trabalhos de Enright e Newton (2004) e de 
Taberner (2007), para avaliar a performance desagregada de cada uma das 36 variáveis testadas. Mais adiante são relatados os resultados da Análise Fatorial Exploratória e a avaliação da confiabilidade dos fatores (Alfas de Cronbach), através dos quais são identificadas as dimensões de análise que servem de referência para comparação da competitividade do destino em relação aos destinos concorrentes.

\section{Resultados}

A amostra é predominantemente feminina $(68,8 \%)$ e composta por pessoas com ensino superior. Entre as ocupações dos respondentes preponderam os estudantes da área gerencial (aí incluídos os estudantes de turismo e de hotelaria) (31\%) e os estudantes de outras áreas (30\%). Uma parcela expressiva da amostra $(84,4 \%)$ era formada por residentes do próprio destino avaliado, e $80,7 \%$ se disseram viajantes frequentes (pessoas que viajam uma ou mais vezes ao ano a passeio).

A importância dos atributos, para fins da Análise de Importância e Desempenho (eixo vertical) foi calculada a através da distribuição de frequências destes nas posições ordinais, multiplicadas pela força relativa de cada posição. Como a questão solicitava aos respondentes que ordenassem os atributos de menor para maior (o mais importante primeiro e o menos importante por último), foi necessário inverter a ordem, de maneira que o primeiro recebesse peso $n$, o segundo $n-1$, o terceiro $n-2$, e assim sucessivamente. Assim, por exemplo, um atrativo turístico (dos 16 listados) que fosse apontado por 10 respondentes como "o mais importante de todos" (primeira posição), como o segundo mais importante por 20 respondentes, e como o terceiro por mais 30 pessoas, somaria 880 pontos $[(10 \mathrm{X} \mathrm{16})+(20 \mathrm{X}$ $15)+(30 \mathrm{X}$ 14) $]$. Por se tratar de uma medida relativa, um valor de referência utilizado apenas para localizar os pontos no eixo vertical do gráfico, os valores identificados poderiam ter sido normalizados de forma conveniente (ex.: entre $0|----| 10$, ou entre $-2|----|+2$ ). Entretanto, para facilitar a compreensão do método, optou-se por manter e apresentar os valores conforme calculados (entre 600|----|1800). 
Tabela 1 - Atributos Testados

\begin{tabular}{l|l}
\hline \multicolumn{1}{c|}{$\begin{array}{c}\text { Atributos diretamente } \\
\text { relacionados ao turismo }\end{array}$} & Atributos facilitadores do turismo \\
\hline Apelo visual & Acesso à informação \\
Arquitetura interessante & Apoio governamental ao turismo \\
Atrações dedicadas ao turismo & Capacidade gerencial (empresas locais) \\
Clima & Comércio varejista \\
Culinária / Gastronomia & Condição da economia como um todo \\
Cultura diferente & Cooperação interfirmas \\
Eventos especiais & Custo da força de trabalho \\
Festivais & Estabilidade política no longo prazo \\
História notável & Estrutura de comunicação \\
Hospitalidade/Receptividade da & Estrutura de transporte \\
população local & \\
Modo de vida local & Fácil acesso (nacional/internacional) \\
Museus e galerias & Incentivo ao investimento \\
Música e espetáculos & Instituições de ensino e de treinamento \\
Referências bem conhecidas & Localização geográfica \\
Segurança & Potencial p/ turismo longa distância \\
Vida noturna & Presença de empresas internacionais \\
& Qualidade da força de trabalho \\
& Qualidade das acomodações \\
& Sistema bancário e financeiro em geral \\
& Transparência política em nível local \\
\hline
\end{tabular}

Fonte: Adaptado de Enright e Newton (2004)

A performance competitiva do destino foi levantada através de questões intervalares de cinco pontos, que iam de "muito pior" até "muito melhor" que o principal concorrente identificado pelos próprios respondentes. O resultado aponta como principais forças de atração do destino, a sua história notável e a existência de uma arquitetura interessante (quadrante superior direito), e como principais debilidades (atributos de grande importância e fraco desempenho) a ausência de atrações dedicadas ao turismo e a falta de uma melhor culinária e gastronomia. Outros atributos vistos como importantes, como a hospitalidade e a receptividade da população, aparecem mais ou menos empatados com o principal concorrente identificado por cada um. 


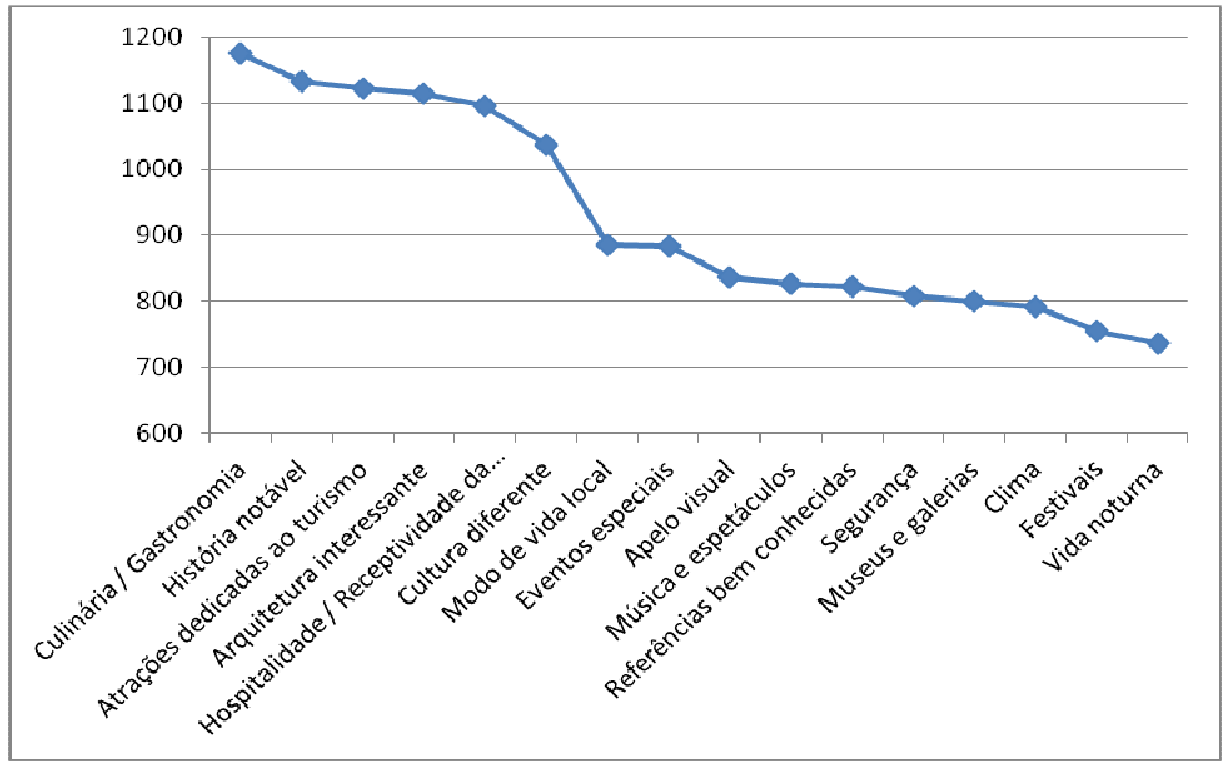

Figura 1 - Importância relativa dos atributos diretamente ligados ao turismo.

Fonte: pesquisa direta, 2014.

Entre as variáveis diretamente ligadas ao turismo, o resultado sugere a existência de dois grupos: um grupo de alta e outro de baixa importância. Conforme se vê na Figura 1, os respondentes pesquisados apontam como mais importante: a culinária e a gastronomia, a história, as atrações diretamente dedicadas ao turismo, a arquitetura, a hospitalidade e a receptividade da população residente e a existência de uma cultura diferente. Atributos como clima, festivais e vida noturna e outros são vistos pelos respondentes como menos importantes.

Entre os atributos facilitadores - aqueles que se relacionam apenas indiretamente com o turismo - os respondentes destacam a importância do acesso para turistas de longa distância, a localização geográfica, o acesso à informação, a qualidade das acomodações, o apoio governamental à atividade, entre outros. Ao contrário do que ocorre com os atributos diretamente ligados ao turismo, aqui não se vislumbra uma separação nítida entre atributos de grande e de pequena importância. Conforme se vê na Figura 2, ainda que exista uma ordem nitidamente decrescente, não há qualquer sinal de perda abrupta de importância entre os atributos, como ocorre no grupo anterior. 


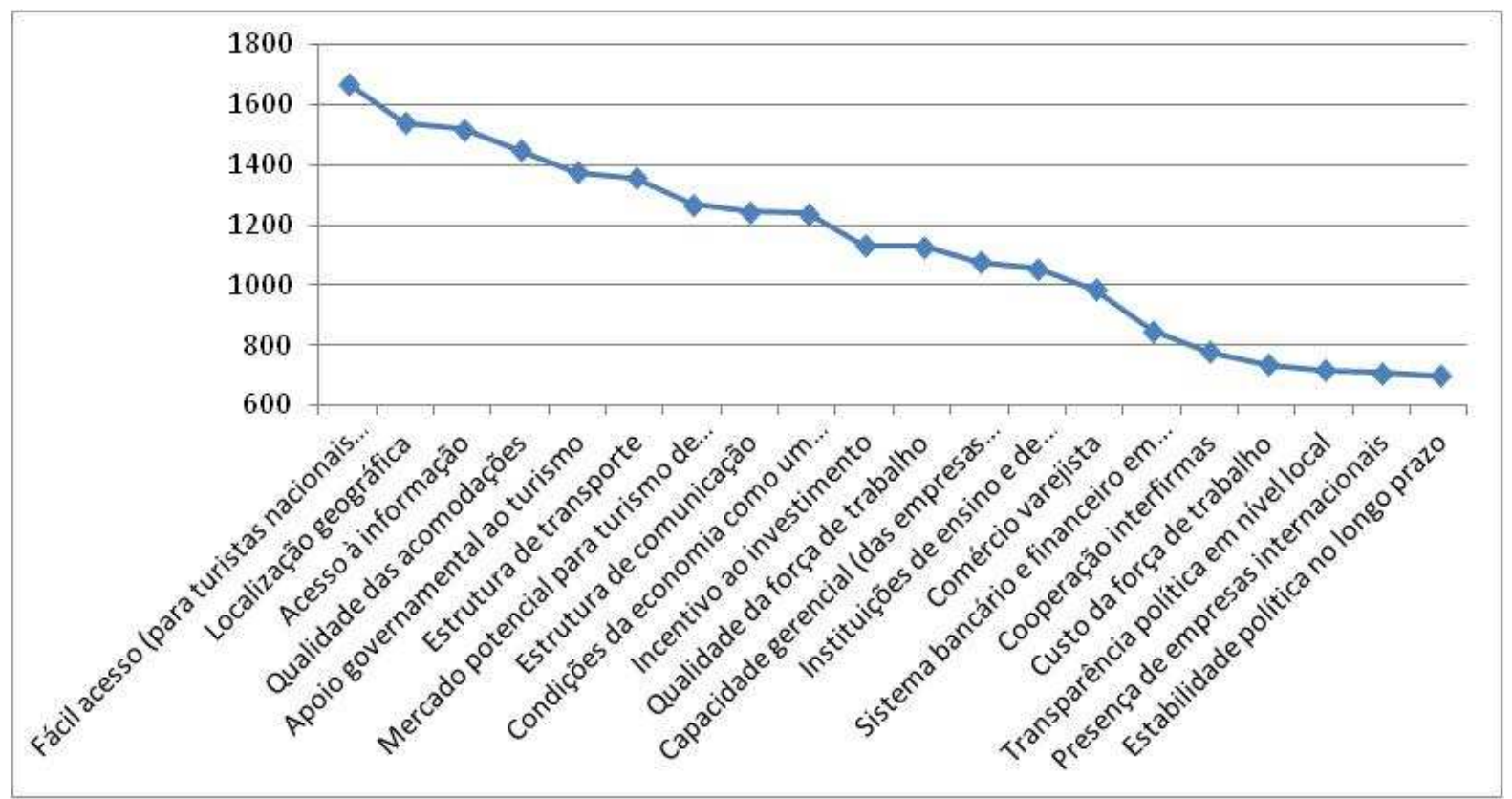

Figura 2 - Importância relativa dos atributos facilitadores do turismo.

Fonte: pesquisa direta, 2014.

Conforme se vê pela Figura 3, o resultado destaca também a existência de uma vida noturna interessante, um atributo no qual o destino avaliado supera os seus concorrentes, mas que, na visão dos respondentes, tem baixa importância relativa para a competitividade do destino. A cidade peca também pelo baixo apelo visual e pela falta de segurança, de festivais, de espetáculos, de eventos especiais e de referências bem conhecidas e divulgadas, deficiências estas que uma vez corrigidas, poderiam ajudar a melhorar a competitividade do destino. 


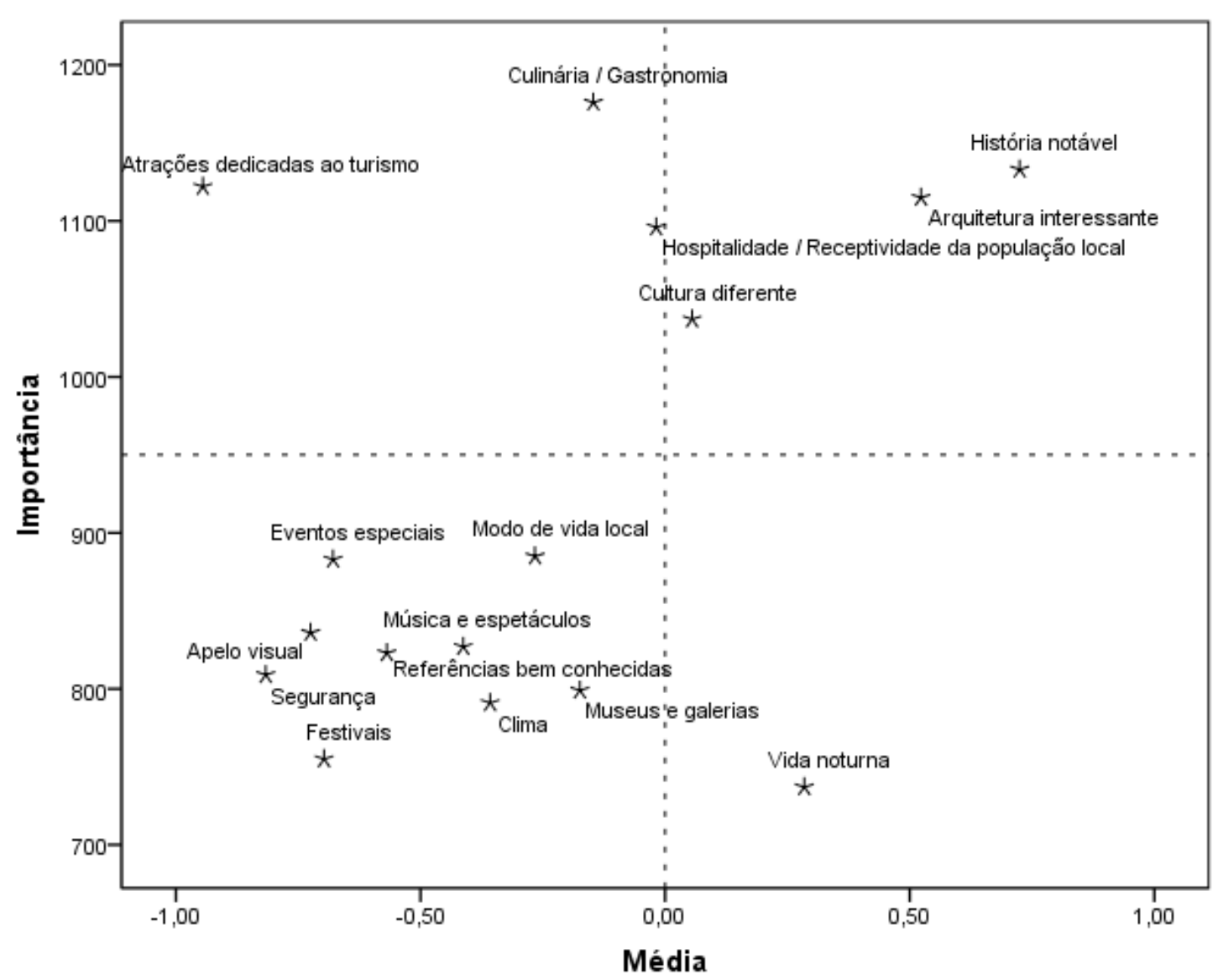

Figura 3 - Competitividade do destino interiorano revelado através dos atributos diretamente ligados ao turismo.

Fonte: pesquisa direta, 2014.

A análise da competitividade obtida a partir das variáveis facilitadoras - mas não diretamente relacionadas ao turismo - apresenta um cenário preocupante. No conjunto de variáveis consideradas como "as mais importantes para a atratividade do destino", a avaliação do destino é bastante baixa; e aquelas nas quais o destino apresenta performance superior à concorrência são variáveis consideradas de pequena importância relativa.

Conforme se vê na metade superior da Figura 4, variáveis consideradas vitais para a atratividade, como a facilidade de acesso para turistas de longa distância, o acesso à informação, a estrutura de transporte, o apoio governamental ao turismo e a qualidade das instalações são avaliadas de forma negativa em relação à concorrência. E algumas variáveis nas quais o destino se destaca, como a existência de instituições de ensino e treinamento, a 
qualidade do comércio varejista e do sistema bancário, são consideradas menos importantes para criar diferenças competitivas em relação à concorrência.

Algumas variáveis de natureza organizacional, nas quais o destino também tem avaliação bastante débil, são consideradas menos problemáticas, tendo em vista a baixa importância relativa que lhes é atribuída. Conforme se vê no quadrante inferior esquerdo da Figura 4, encontram-se nessa condição o incentivo ao investimento, a qualidade da força de trabalho, a capacidade gerencial das empresas, a cooperação interfirmas, a transparência política e a presença de empresas internacionais na região.

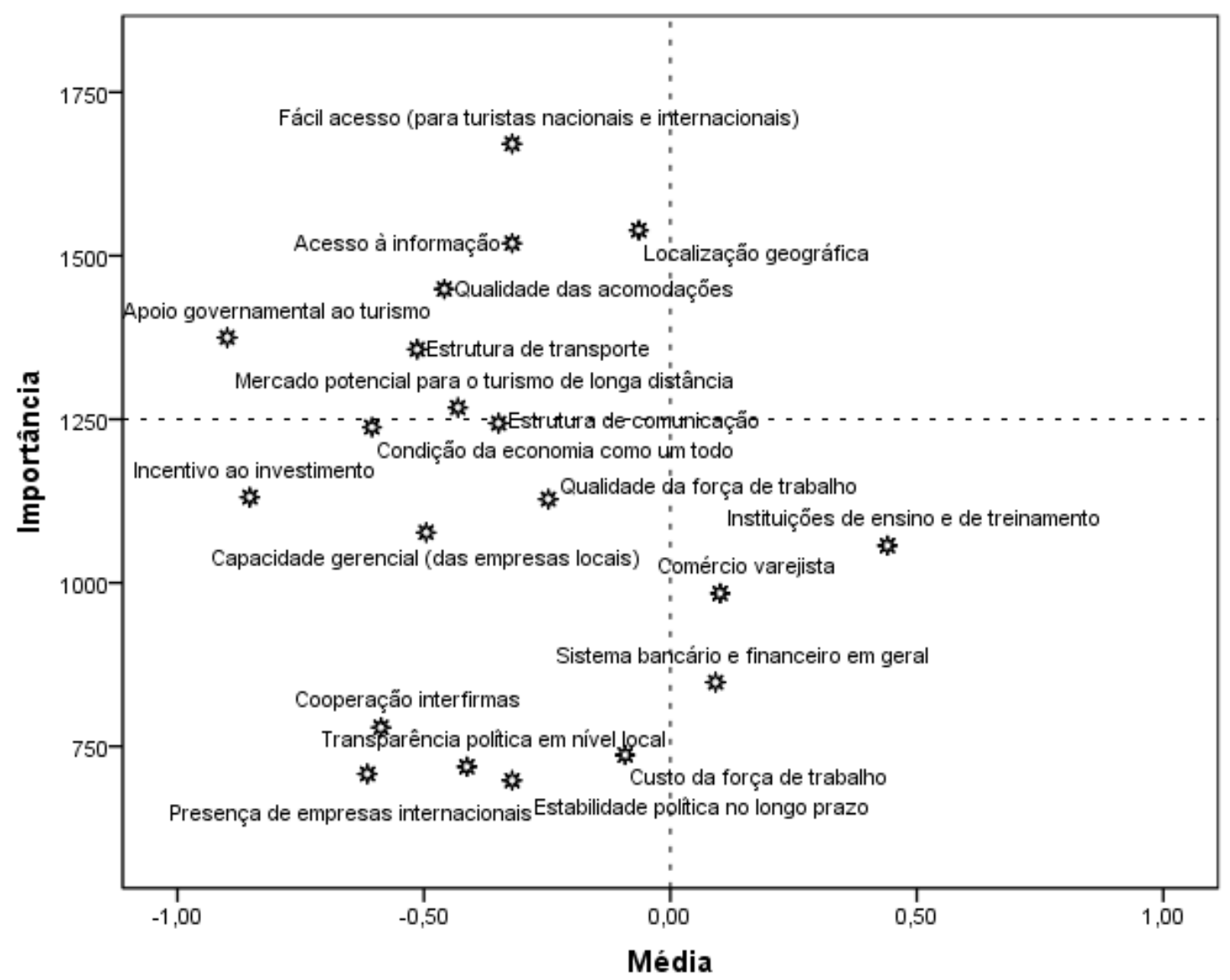

Figura 4- Competitividade do destino interiorano revelado através dos atributos facilitadores do turismo.

Fonte: pesquisa direta, 2014.

Após a análise desagregada, realizada através da AID, foi realizada Análise Fatorial Exploratória (AFE), para identificar um conjunto menor de dimensões que facilitasse a 
interpretação dos fenômenos e permitisse a comparação do destino aos concorrentes identificados (HAIR JR. et al., 2005). Por se tratar de conjuntos distintos de variáveis, os atributos diretamente relacionados ao turismo e as variáveis organizacionais (facilitadoras do turismo) foram tratados separadamente. O método utilizado para identificação das diferentes dimensões foi a Análise de Componentes Principais e o número de fatores identificados em cada conjunto de atributos foi definido com base nos critérios recomendados por Costello e Osborne (2005): autovalores superiores a um, rotação oblíqua, fatores com três itens ou mais e poucas (ou nenhuma) cargas cruzadas.

Tabela 2 - Atrativos diretamente ligados ao turismo (Fatores Identificados)

\begin{tabular}{|c|c|c|c|}
\hline \multirow[b]{2}{*}{ Variáveis } & \multicolumn{3}{|c|}{ Cargas Fatoriais } \\
\hline & $\begin{array}{l}\text { Entretenimen } \\
\text { to }\end{array}$ & $\begin{array}{l}\text { Acolhimento } \\
\text { ao Turista }\end{array}$ & $\begin{array}{l}\text { Patrimôn } \\
\text { io } \\
\text { Cultural }\end{array}$ \\
\hline Música e espetáculos & 0,861 & & \\
\hline Eventos especiais & 0,705 & & \\
\hline Museus e galerias & 0,686 & & \\
\hline Festivais & 0,678 & & \\
\hline Vida noturna & 0,669 & & \\
\hline Culinária / Gastronomia & 0,457 & 0,419 & \\
\hline Segurança & & 0,801 & \\
\hline Modo de vida local & & 0,740 & \\
\hline Apelo visual & & 0,699 & \\
\hline Hospitalidade/Receptividade da população & & 0,665 & \\
\hline $\begin{array}{c}\text { local } \\
\text { Atrações dedicadas ao turismo }\end{array}$ & 0,363 & 0,492 & \\
\hline História notável & & & 0,830 \\
\hline Arquitetura interessante & & & 0,730 \\
\hline Cultura diferente & & 0,498 & 0,511 \\
\hline Alfa de Cronbach & 0,786 & 0,766 & 0,618 \\
\hline
\end{tabular}

Obs.: Método de Extração: Principal Component Analysis. Rotação: Oblimin with Kaiser Normalization.

Fonte: pesquisa direta, 2014.

Foram identificados três fatores com autovalores superiores a um, os quais, em conjunto explicam 57,55\% da variância. Duas das 16 variáveis (clima e referências bem conhecidas) apresentaram altas cargas cruzadas e por essa razão foram excluídas da análise. As três dimensões nas quais se agrupam as variáveis representativas dos atributos turísticos foram analisadas e nomeadas como: "Entretenimento", "Acolhimento ao Turista" e "Patrimônio 
Cultural". Todos os fatores apresentaram cargas fatoriais e Alfas de Cronbach superiores ao mínimo recomendado de 0,6 para trabalhos exploratórios (HAIR JR. et al., 2005). Três variáveis (Culinária/Gastronomia, Atrações Dedicadas ao Turismo e Cultura Diferente) apresentaram cargas cruzadas, mas mesmo assim foram mantidas no modelo, tendo em vista a importância que lhes foi atribuída na etapa anterior e considerando que a escala que está sendo sugerida encontra-se ainda em construção. A lista de variáveis identificadas, os fatores correspondentes e os Alfas de Cronbach respectivos encontram-se listados na Tabela 2.

Os atributos facilitadores do turismo, também se organizaram em três fatores com autovalores superiores a um, explicando ao todo 58,73\% da variância. Quatro dos 20 atributos testados precisaram ser excluídos da análise por apresentarem cargas muito baixas ou cruzadas em mais de um fator: Qualidade da Força de Trabalho, Custo da Força de Trabalho, Acesso à Informação e Presença de Empresas Internacionais.

O primeiro dos três fatores reúne variáveis referentes à estrutura política e à capacidade empresarial e foi nomeada como "Administração Pública e Cultura Empreendedora"; o segundo fator reúne variáveis referentes à "Estrutura de Serviços"; e o terceiro corresponde à "Facilidade de Acesso para os Turistas". Todos os fatores apresentaram cargas fatoriais e Alfas de Cronbach superiores ao mínimo recomendado de 0,6 para trabalhos exploratórios (HAIR JR. et al., 2005). Dois itens, a estrutura de comunicação e o mercado potencial para o turismo de longo curso apresentaram cargas cruzadas, mas foram mantidas no modelo tendo em vista a importância que lhes foi atribuída na etapa anterior. A lista de variáveis identificadas, os fatores correspondentes e os Alfas de Cronbach respectivos encontram-se listados na Tabela 3. 
Tabela 3 - Atributos Facilitadores do Turismo (Fatores Identificados)

\begin{tabular}{|c|c|c|c|}
\hline \multirow[b]{2}{*}{ Variáveis } & \multicolumn{3}{|c|}{ Cargas Fatoriais } \\
\hline & $\begin{array}{l}\text { Administração pública e } \\
\text { cultura empreendedora }\end{array}$ & $\begin{array}{l}\text { Estrutura de } \\
\text { Serviços }\end{array}$ & $\begin{array}{c}\text { Facilidade de } \\
\text { Acesso para os } \\
\text { Turistas }\end{array}$ \\
\hline $\begin{array}{l}\text { Estabilidade política no } \\
\text { longo prazo }\end{array}$ & 0,850 & & \\
\hline $\begin{array}{l}\text { Transparência política em } \\
\text { nível local }\end{array}$ & 0,767 & & \\
\hline $\begin{array}{l}\text { Condição da economia } \\
\text { como um todo }\end{array}$ & 0,698 & & \\
\hline Incentivo ao investimento & 0,698 & & \\
\hline Cooperação interfirmas & 0,655 & & \\
\hline $\begin{array}{l}\text { Apoio governamental ao } \\
\text { turismo }\end{array}$ & 0,621 & & \\
\hline Estrutura de transporte & 0,618 & & \\
\hline $\begin{array}{l}\text { Capacidade gerencial (das } \\
\text { empresas locais) }\end{array}$ & 0,505 & & \\
\hline $\begin{array}{l}\text { Instituições de ensino e de } \\
\text { treinamento }\end{array}$ & & 0,848 & \\
\hline $\begin{array}{l}\text { Sistema bancário e } \\
\text { financeiro em geral }\end{array}$ & & 0,789 & \\
\hline Comércio varejista & & 0,715 & \\
\hline Estrutura de comunicação & 0,394 & 0,488 & \\
\hline Localização geográfica & & & $-0,847$ \\
\hline Qualidade das acomodações & & & $-0,647$ \\
\hline $\begin{array}{l}\text { Fácil acesso (para turistas } \\
\text { nacionais e internacionais) }\end{array}$ & & & $-0,637$ \\
\hline $\begin{array}{l}\text { Mercado potencial para o } \\
\text { turismo de longa distância }\end{array}$ & 0,382 & & $-0,417$ \\
\hline Alfa de Cronbach & 0,872 & 0,720 & 0,763 \\
\hline
\end{tabular}

Obs.: Extraction Method: Principal Component Analysis. Rotation Method: Oblimin with Kaiser Normalization.

Fonte: pesquisa direta, 2014.

Após identificadas as variáveis formadoras de cada fator e avaliada a confiabilidade dos mesmos, estes foram reduzidos pelas médias à condição de novas variáveis para efeito de comparação. Este procedimento se fez necessário para que se pudesse comparar a performance do destino avaliado aos seus concorrentes mais próximos.

Conforme se vê na Figura 5, o patrimônio cultural do destino interiorano (a sua maior força) é melhor avaliado que a maioria dos concorrentes apontados, perdendo apenas para destinos tradicionais como Montevidéu, Ouro Preto, Rio de Janeiro e São Miguel das Missões. A 
estrutura de acolhimento, porém, fica muito aquém do desejado: supera em qualidade apenas Piratini, Santa Maria e São Miguel das Missões; e tem avaliação pior do que todos os demais destinos apontados como concorrentes, em especial Canela e Rio de Janeiro, apontados como os melhores naquele fator. A estrutura de entretenimento tem avaliação apenas razoável: supera alguns concorrentes próximos, como Bento Gonçalves, São Lourenço do Sul e Jaguarão, mas fica bem abaixo dos destinos consolidados, como Canela, Gramado, Rio de Janeiro, Porto Alegre e Montevidéu.

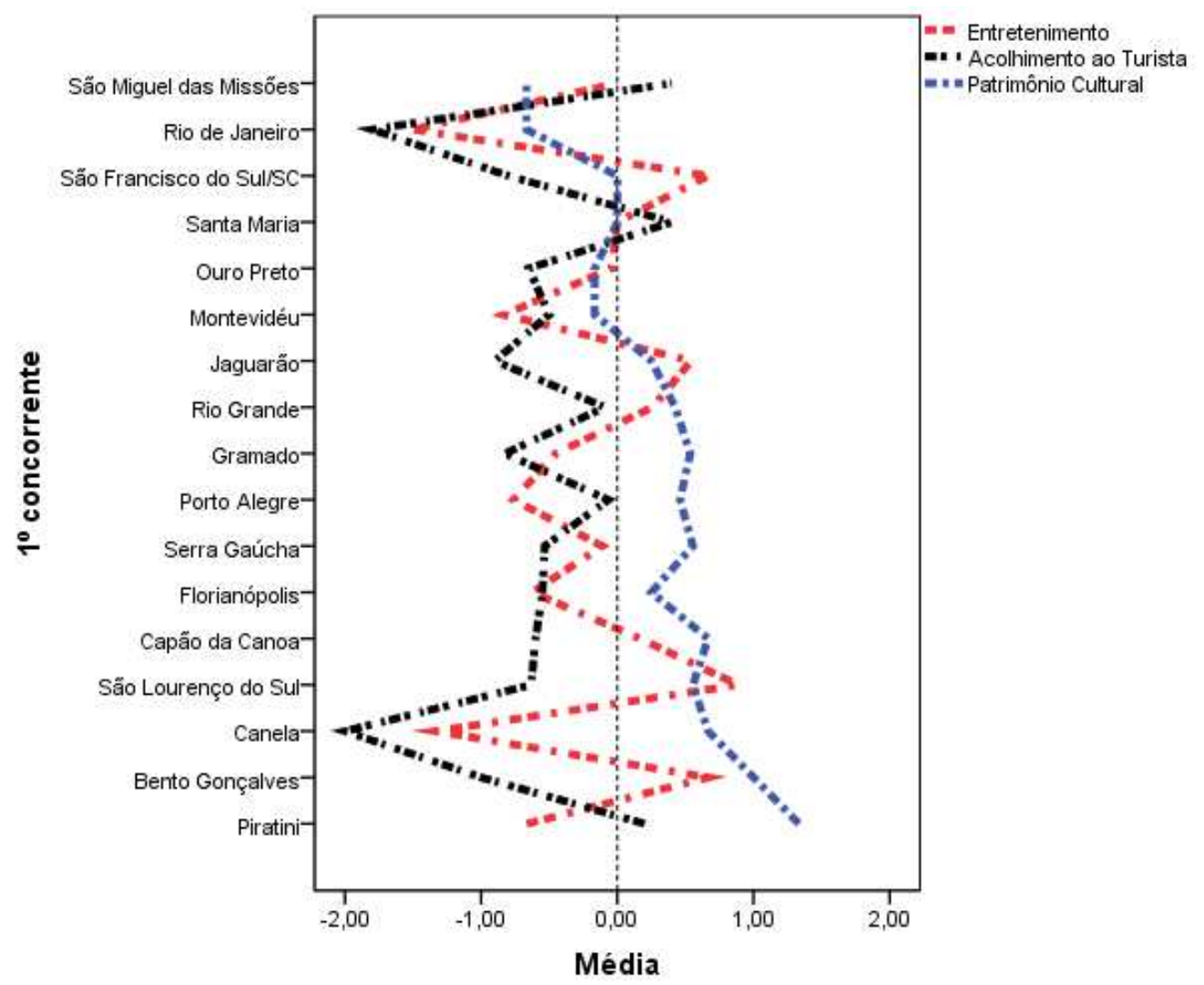

Figura 5 - Performance em relação aos principais concorrentes (Fatores Diretamente Relacionados ao Turismo)

Fonte: pesquisa direta, 2014.

Em relação aos fatores facilitadores do turismo (atributos organizacionais ligados indiretamente ao setor), a avaliação do destino pesquisado é bastante crítica. A estrutura de serviços supera a dos municípios da Serra Gaúcha e alguns outros menores, como São Francisco do Sul, São Lourenço do Sul, São Miguel das Missões e Rio Grande, mas perde para cidades maiores como Santa Maria, Porto Alegre, Florianópolis e Montevidéu. 
A avaliação da administração pública e da (falta de) cultura empreendedora na cidade sugere estar ali a sua maior vulnerabilidade enquanto destino turístico. Conforme se vê na Figura 6, a avaliação supera apenas São Francisco do Sul, Santa Maria e Piratini, neste fator, e perde longe para os municípios da Serra Gaúcha, Porto Alegre, Rio Grande, Rio de Janeiro e vários outros destinos.

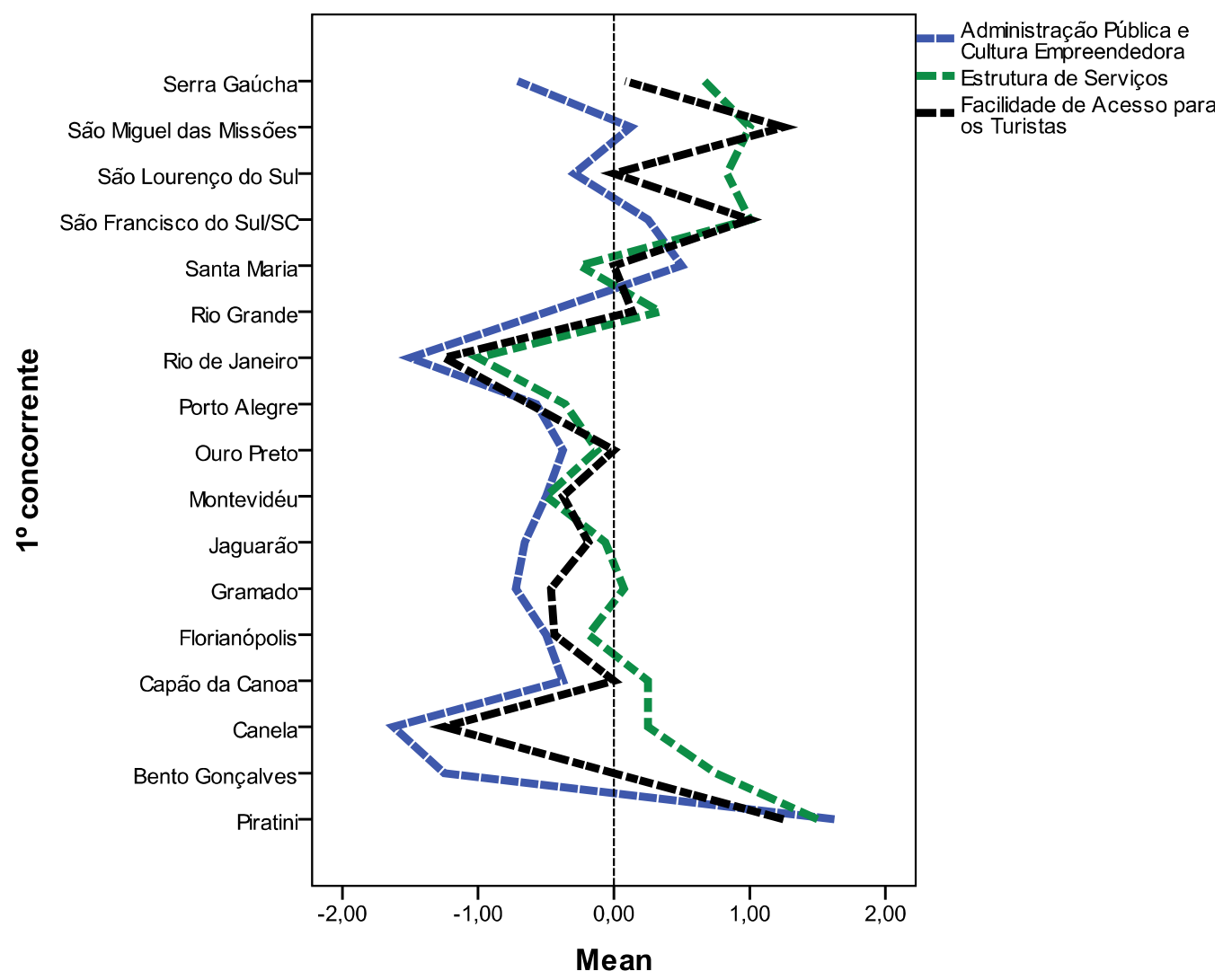

Figura 6 - Performance em relação aos principais concorrentes (Fatores Facilitadores do Turismo).

Fonte: pesquisa direta, 2014.

A facilidade de acesso também se constitui num limitador importante do turismo, na visão dos respondentes. Entre os concorrentes apontados, o destino interiorano tem melhor acesso em relação a apenas três destinos longínquos: São Miguel das Missões, São Francisco do Sul e Piratini. Praticamente todos os demais destinos comparados têm acesso melhor ou igual ao destino pesquisado, especialmente Porto Alegre, Canela, Gramado e Rio de Janeiro. 


\section{Considerações Finais}

O presente estudo não ambiciona inovar sobre as bases conceituais da competitividade de destinos em si, tendo em vista que a definição do construto já se encontra suficientemente madura; mas ambiciona apresentar uma forma inovadora de medi-lo e analisá-lo. O trabalho inova sobre a literatura revisada, ao propor um método de mensuração que vai além da simples representação gráfica dos atributos formadores da competitividade dos destinos turísticos; um método predominantemente quantitativo, que permite analisar as forças e fraquezas do destino em comparação aos concorrentes, assim como estabelecer indicadores de performance ao longo do tempo, preenchendo um vazio da literatura nacional, cujos estudos sobre o tema ainda se limitam à abordagem qualitativa (MIKI, GÂNDARA ; MUÑOZ, 2012).

A avaliação da competitividade baseada numa Matriz de Importância e Desempenho (IPAGrid), conforme fizeram Enright e Newton (2004) e Taberner (2007), tem o mérito de representar graficamente os vetores de competitividade e a partir destes identificar as principais forças e fraquezas de cada destino. Mas apesar do mérito, o método não permite que se faça inferências estatísticas sobre a performance competitiva de um destino ao longo do tempo, ou em relativamente a destinos concorrentes; como se trata de um método subjetivo-interpretativo, um mesmo destino pode ser considerado altamente competitivo para um analista e parecer nada competitivo aos olhos de outro. O método empregado no presente trabalho permite identificar os principais concorrentes do destino, e a partir da aglutinação de variáveis em dimensões de análise (fatores), comparar o seu desempenho ao dos concorrentes identificados e criar indicadores de longo prazo.

Os resultados precisam ser tomados com o devido cuidado, tendo em vista que a amostra tem grande parcela de estudantes e foi colhida por conveniência, através da internet, não permitindo maior controle sobre os respondentes. Longe de esgotar o assunto, o presente artigo apenas aponta um caminho a ser trilhado. Novos estudos são necessários, especialmente estudos de natureza confirmatória, tanto para avaliar a adequação do elenco de variáveis aqui sugeridas, como para avaliar a confiabilidade e a validade (convergente, discriminante e de face) dos fatores identificados. É importante também que futuros estudos empreguem amostras probabilísticas, colhidas em destinos de diferentes tipos e portes, para avaliar a capacidade de generalização do método que está sendo proposto, com vistas a uma possível universalização. 


\section{Referências}

BEARDEN, W. O., NETEMEYER, R. G.; HAWS, K. L. Handbook of marketing scales: Multi-item measures for marketing and consumer behavior research. (3rd ed.). Thousand Oaks, CA: SAGE Publications, Inc.. 2011.

BUHALIS, D. Marketing the competitive destination of the future. Tourism Management, 21, 97-116. 2000.

CHURCHILL, G.A., JR. A Paradigm for Developing Better Measures of Marketing Constructs. Journal of Marketing Research, 16(1), 64-73. 1979.

COOPER, C., FLETCHER, J., GILBERT, D., SHEPHERD, R.,; WANHILL, S. Tourism Principles and Practices, 2ed., England: Addison-Wesley, Longman. 1998.

COSTELLO, A. B.; OSBORNE, J. W. Exploratory Factor Analysis: Four recommendations for getting the most from your analysis. Practical Assessment, Research, and Evaluation, 10(7), 1-9. 2005.

CROMPTON, J.L.; DURAY, N.A. An investigation of the relative efficacy of four alternative approaches to importance-performance analysis. Journal of the Academy of Marketing Science, 13(4), 69-80. 1985.

CROUCH. Modelling Destination Competitiveness: A Survey and Analysis of the Impact of Competitiveness Attributes, CRC for Sustainable Tourism Pty Ltd, Queensland, Australia. 2007.

CROUCH, G.I.; RITCHIE, J.R.B. Tourism, Competitiveness and Societal Prosperity, Journal of Business Research, 44(3), 137-152. 1999.

DWYER, L.; KIM, C. Destination Competitiveness: determinants and indicators. Current Issues in Tourism, 6, 369-414. 2003.

ENRIGHT, M. J.; NEWTON, J. Tourism Destination Competitiveness: A Quantitative Approach, Tourism Management, 25 (6), 777-878. 2004.

ENRIGHT, M. J.; NEWTON, J. Determinants of Tourism Destination Competitiveness in Asia Pacific: Comprehensiveness and Universality, Journal of Travel Research. 43, 339-350. 2005.

GOOROOCHURN, N.; SUGIYARTO, G. Competitiveness Indicators in Travel and Tourism Industry, Tourism Economics, 11(1), 25-43. 2005.

HAIR JR., J. F., ANDERSON, R. E., TATHAM, R. L., ; BLACK, W. C. Análise multivariada de dados. 5. ed. Porto Alegre: Bookman. 2005.

MAZANEC, J.A., WÖBER, K.; ZINS, A.H. Tourism destination competitiveness: from definition to explanation, Journal of Travel Research, 46, 86-95. 2007.

MIKI, A.F.C., GÂNDARA, J.M.G.; MUÑOZ, D.R.M. O estado atual de pesquisas sobre competitividade turística no Brasil. Caderno Virtual de Turismo. 12(2), 212-223. 2012.

RITCHIE, J.R.B.; CROUCH, G.I. The Competitive Destination: A Sustainability Perspective, Tourism Management, 21(1), 1-7. 2000.

RITCHIE, J.R.B.; CROUCH, G.I. The Competitive Destination: A Sustainable Tourism Perspective, CABI Publishing, Wallingford, UK. 2003.

TABERNER, J. G. Propuesta de dos índices para la medición de la competitividad de los destinos de sol y playa del Mediterráneo: avance de resultado, Revista de Análisis Turístico, nº 4, 50-67. 2007.

\section{Recebido em: 22/10/2015}

Aprovado em: 15/12/2015 